\title{
Semantics and Pragmatics in the Interpretation of or
}

\author{
Mandy Simons \\ Carnegie Mellon University
}

\section{Introduction}

This paper concerns what might be called the variably bad behavior of the word $o r$. As is well known, there are a variety of environments in which the word or misbehaves - misbehaves, in the sense that it gives rise to interpretations which are not expected given the standard analysis of this word as, roughly, set union. One of these environments is the scope of a modal. This case has received a lot of attention recently in the literature, and a number of researchers, including myself, have proposed accounts of or which explain its behavior in this environment.

But here is where the problem arises: When we embed or under both a modal and negation, it stops misbehaving and starts acting again like a well behaved Boolean operator. This is problematic for those of us who have gone to some lengths to argue, on the basis of the affirmative cases, that or isn't a Boolean operator at all.

In this paper, I will of fer an explanation for this variable misbehavior. I will propose that or is, after all, more or less a Boolean operator, although one which works in a somewhat special way. In addition, I will argue that or coordinations are subject to a special constraint, called Symmetry; and that it is the requirement to satisfy Symmetry which sometimes forces or to display apparently non-Boolean behavior.

\section{Modals, Negation, and or}

We begin with sentences in which a phrasal or coordination is embedded under a modal and negation, as in sentences (1)-(2).

(1) Jane may not sing or dance.

(2) Jane must not sing or dance.

Let's begin by investigating the may sentence in (1); we'll come back to the must sentence afterwards.

Sentence (1) has two possible readings, which are represented using standard logical notation in (3)-(4).

(3) $\neg \diamond($ jane sing) $\wedge \neg \diamond$ (jane dance) "neither reading"

(4) $\neg \diamond$ (jane sing) $\vee \neg \diamond$ (jane dance) "disjunctive reading"

On the neither reading sentence (1) means that both activities are forbidden for Jane. On the disjunctive reading, the sentence means that at least one of the activities is 
forbidden. The neither reading is generally most salient. But the dis junctive reading can be brought out by appending to sentence one the continuation, "...but I don't know which."

The neither reading is the easycase. This is the reading derivable by standard treatments of or, of which Partee and Rooth's (1983) Generalized Disjunction account is representative. According to this account, an or coordination denotes the Boolean join (set union) of its disjuncts. So, assuming that sentence (1) has an LF with the structure shown in (5), its translation proceeds as shown in (6), with the final result having the truth conditions (at world $w^{*}$ ) shown in (7).

(5) $\operatorname{not}[$ may [ jane [sing or dance] ] ]

(6) (i) sing or dance $=\lambda$ v.sing(v) $\vee$ dance(v)

(ii) jane sing or dance $\Rightarrow \operatorname{sing}(\mathrm{j}) \vee$ dance(j)

(iii) not [ may [ jane [sing or dance] ] ] ==> $\neg$ may $(\operatorname{sing}(j) \vee$ dance(j))

$\neg \exists \mathrm{w}^{\prime} \in \mathrm{ACC}_{\mathrm{w}^{*}}: \mathrm{w}^{\prime} \in\{\mathrm{w}: \mathrm{jane}$ sings at $\mathrm{w}\} \cup\{\mathrm{w}:$ jane dances at $\mathrm{w}\}$

i.e. iff there is no permissible world in which Jane sings or dances. ${ }^{1}$

These truth conditions are indeed those of the neither reading of (1).

The problem is that these are the only truth conditions predicted for sentence (1). The Generalized Disjunction strategy alone cannot derive the truth conditions of the disjunctive reading, without the help of some complex syntactic assumptions.

\subsection{A Solution: or Coordinations as Sets}

We can account for the ambiguity of (1) without positing either lexical or structural ambiguity, if we adopt an analysis of or coordinations which allows semantic composition to proceed in more than one way. In an earlier paper (Simons 2005), I proposed that an or coordination denotes a set whose members are the denotations of the (ordinary) denotations of the dis juncts. (Cf. related proposals in Winter 1995, 2000, and Kratzer and Shimoyama 2002.) So, for example, the coordination sing or dance denotes the set in (8).

$$
\text { \{[sing], [dance]\} }
$$

Now, once we admit such objects as denotations, the question immediately arises: how do such denotations combine with the denotations of other expressions? The answer is given by the Rule of Independent Composition, whose effects are represented schematically in (9):

$$
\begin{gathered}
\mathrm{A}_{\mathrm{a}}=\{\mathrm{a}(c), \mathrm{b}(c)\} \\
c_{\mathrm{c}}=\mathrm{C} \quad \mathrm{B}=\left\{\mathrm{a}_{<\mathrm{c}, \mathrm{a}>>} \mathrm{b}_{<\mathrm{c}, \mathrm{a}>}\right\}
\end{gathered}
$$


Here is the general idea: Let $A$ be a node with daughters $C$ and $B$. Let $C$ have an ordinary denotation of type $c$, while $\mathrm{B}$ is a disjunctive expression denoting a set of objects each of which is of type $<\mathrm{c}, \mathrm{a}>$. Then $\mathrm{A}$ also denotes a set, whose members are the result of combining each of the members of the denotation of $B$ independently with the denotation of $C$. The formal version of the rule is given in (10):

(10) Rule of Independent Composition

(i) Let $\alpha$ be a branching node with daughters $\beta$ and $\gamma$, where $[\beta] \in D_{<b, a>}$ and $[\gamma] \subseteq D_{b}$. Then $[\alpha]=\{a: \exists g \in[\gamma] \cdot[\beta](g)=a\}$.

(ii) Let $\alpha$ be a branching node with daughters $\beta$ and $\gamma$, where $[\beta] \subseteq D_{<b, a>}$ and $[\gamma] \in D_{b}$. Then $[\alpha]=\{a: \exists b \in[\beta] .[\gamma](b)=a\}$.

(Cf. Hamblin 1973, Kratzer and Shimoyama 2002, Winter 1995)

With these assumptions in hand, it is quite straightforward to derive the dis junctive reading of sentence (1). I repeat the sentence here, with its presumed LF:

(1) Jane may not sing or dance.

not [ may [ jane [sing or dance] ]]

The expression sing or dance, by assumption, has the denotation shown in (8) above. Now this must combine with the subject, Jane. The result of independent composition is the set shown in (11).

\{[jane sing], [jane dance]\}

This set now combines with the modal, also by independent composition, giving:

$$
\{[\text { may]([jane sing]), [may]([jane dance] })\}
$$

And finally, this set combines with negation by independent composition, giving:

$$
\{[\text { not][may]([jane sing]), [not][may]([jane dance])\} }
$$

i.e. a set whose members are the proposition that Jane may not sing and the proposition that Jane may not dance.

Now, the final question to be answered is: what do we do at the top of the tree? How do we convert a set of denotations into an ordinary sentence denotation? The answer I give here departs from my earlier proposal. The new proposal is simple: allow that a set originally introduced by or can be simplified at any point via set union. ${ }^{2}$ In this case, the application of union to the set at the top of the tree results in a set of possible worlds: all those worlds at which Jane does not sing and all those worlds at which Jane does not dance i.e. just the proposition denoted by sentence (1) on its dis junctive reading.

To summarize, then, here is the proposal as to how or coordinations are interpreted: the coordination itself denotes a set whose members are the denotations 
of the disjuncts. This set composes with a sister node in one of two ways. The first way is through application of the Rule of Independent Composition. The second way is to first apply union to the set, and then proceed with composition in the usual way. (Again, the parallel with Winter's (1995) proposal regarding and coordination should be noted.) In the example just considered, set union was applied at the very end of the derivation, to convert a complex set denotation into an ordinary proposition. I will refer to this analysis of or coordination as the Set Formation analysis.

Before proceeding, we should go back and check that the neither reading of sentence (1), which we derived earlier using Generalized Disjunction, is also derivable in the Set Formation analysis. In fact it is. We proceed in just the same way, but apply the union option at the VP level. Here is how the derivation proceeds. For convenience, I again repeat here the sentence with its presumed LF.

(1) Jane may not sing or dance. not [ may [jane [sing or dance] ] ]

(i) $\operatorname{sing}$ or dance $==>$ [ [sing], [dance] $\}$

(ii) jane sing or dance $\Longrightarrow$ [jane sing], [jane dance] $\}$ (by Independent composition)

(iii) APPLY UNION $==>\cup\{$ [jane sing], [jane dance] $\}$

(iv) $\operatorname{may}[$ jane $[$ sing or dance $]]=>$ [may $] \cup\{$ [jane sing], [jane dance $]\}$ (by ordinary composition)

(v) $\operatorname{not}[$ may $[$ jane $[$ sing or dance $]]] \rightleftharpoons$

[not][may] $\cup\{$ [jane sing], [jane dance] $\}$ (by ordinary composition)

Line (v) gives us exactly the truth conditions we expect: $\neg \exists \mathrm{w} \in \mathrm{ACC}_{\mathrm{w}^{*}}$ s.t. $\mathrm{w} \in\left\{\mathrm{w}^{\prime}:\right.$ jane sings at $\left.\mathrm{w}^{\prime}\right\} \cup\left\{\mathrm{w}^{\prime}:\right.$ jane dances at $\left.\mathrm{w}^{\prime}\right\}$

\subsection{Results for the must Case}

So far, we have shown that both of the readings of sentence (1) can be derived with the Set Formation analysis. We should now go back to the must sentence, and see that its readings are also derivable. Here again is the must sentence, with its presumed LF:

(2) Jane must not sing or dance.

LF: must [not [jane[sing or dance]] $]^{3}$

Like the may version of this sentence, sentence (2) has two interpretations. It too has a disjunctive reading, which is made salient by appending “...but I don't know which". On this reading, the sentence has the truth conditions represented in (15).

$$
\square \frown \text { (jane sing) } \vee \square \neg(\text { jane dance) }
$$


This reading can easily be derived by the strategy outlined above. In fact, we derive it in just the same way as we derived the disjunctive reading of the may sentence: we apply Independent Composition all the way up the tree, then apply the union operation at the top to convert the final pair of propositions into a single proposition.

But for the second reading of the sentence, things are a little more complicated. The second reading of the sentence, because of the reversal of scope between the modal and negation (see note 3 ), is the same as the neither reading of sentence (1), i.e. has the truth conditions represented in (16).

$$
\square \neg \text { (jane sing) } \wedge \neg \neg(\text { jane dance })
$$

So, let's work through a derivation to try to get this reading. Here is our first attempt.

(17) Composition strategy \#1

(i) $\operatorname{sing}$ or dance $=>\{$ [sing],[dance] $\}$

(ii) jane sing or dance $==>$ Ind. comp. $\{$ [jane sing],[jane dance] $\}$

(iii) not jane sing or dance $\left.\Longrightarrow{ }_{\text {Ind comp }}\left\{\text { [jane sing] }{ }^{-} \text {, [jane dance }\right]^{-}\right\}^{4}$

(iv) APPLYUNION $\Longrightarrow \cup\left\{\right.$ [jane sing] ${ }^{-},{\left.\text {[jane dance }]^{-}\right\}}^{-}$

(v) must not jane sing or dance $==>_{\text {standard composition }}[$ must $]\left([\mathrm{Ds}]^{-} \cup[\mathrm{jd}]^{-}\right)$

Line (v) gives us the following truth conditions (for a world $w^{*}$ ):

(18) $\mathrm{ACC}_{\mathrm{w}^{*}} \subseteq\{\mathrm{w}$ : jane does not sing in w or jane does not dance in w $\}$

But wait! We were trying to derive the neither reading of sentence (2). But the truth conditions derived are not those of the neither reading, nor of any reading available for this sentences.

Now, it turns out that there is a second composition strategy available, which does give us the right results. If we apply union earlier - after composition of the subject, as we did in deriving the neither reading of sentence (1) - we do get the correct results, as shown in (19).

(19) Composition strategy \#2:

(i) $\quad$ sing or dance $\Longrightarrow \quad$ [ [sing],[dance] $\}$

(ii) jane sing or dance $==>_{\text {Ind comp }}\{$ [jane sing],[jane dance] $\}$

(iii) APPLY UNION $\Longrightarrow \cup\{$ [jane sing],[jane dance] $\}$

(iv) not jane sing or dance $\Longrightarrow>_{\text {standard composition }}([\mathrm{js}] \cup[\mathrm{jd}])^{-}$

(v) must not jane sing or dance $=>_{\text {standard composition }}[$ must $]\left(([j s] \cup[j \mathrm{~d}])^{-}\right)$

The resulting proposition has the following truth conditions at $\mathrm{w}^{*}$ :

(20) $\mathrm{ACC}_{\mathrm{w}^{*}} \subseteq\{\mathrm{w}$ : jane does not sing or dance in $\mathrm{w}\}$

exactly as desired. So, here's where we stand: We can derive both of the readings of sentence (2) under the Set Formation analysis. But there is another non-existent 
reading which also seems derivable. We still need an explanation for why this reading does not in fact arise. This, we will come back to later.

\subsection{Coordination as Set Formation:Discussion of Parallels with Winter (1995/2000)}

Before moving on to some further data, I would like to pause briefly to consider the ramifications of the parallel, noted above, between my account of or and Winter's treatment of and. Winter (1995) argues that a n and coordination introduces a tuple, whose members correspond to the conjuncts. These tuples can then compose in two ways with their arguments: either by what Winter calls pointwise composition (identical in all relevant respects to my Rule of Independent Composition); or else the tuple can be simplified via set intersection.

In Winter (2000), this strategy is also extended to certain special cases of or coordination. But Winter (1995) argues that and coordination is fundamentally different from or coordination: he claims that the former is syncategorematic, and the latter categorematic. Thus, he argues, the two should not receive parallel treatments. Winter adduces two kinds of evidence for this position. First, he offers crosslinguistic evidence that while conjunction is often morphologically null, dis junction is never so. Second, he claims that disjunction, unlike conjunction, does not show what he calls "structure sensitivity". Let's take each of these claims in turn.

While Winter's cross-linguistic evidence is initially compelling, some facts of English suggest that the situation may be more complicated than he suggests. Consider utterances such as (21) and (22).

(21) Don't poke the cat, she'll scratch you.

(22) You need to bring an umbrella, you're going to get soaked.

There is no overt connective here. If we were to add one, it certainly would not be and. The addition of $o r$, on the other hand, would preserve the intended sense. Now, I would not want to argue that there is an implicit or here. One might equally argue for the presence of an implicit conditional, with the second clause in each case constituting the consequent of an implied antecedent. But certainly, the second clause has to be understood as representing the alternative to fulfilment of the requirement presented in the first. So there is something very "disjunctive" about such utterances. This suggests to me that disjunctive meaning can be expressed in the absence of an overt disjunctive morpheme.

We turn now to Winter's second point, and his notion of structure sensitivity, which is best illustrated by his own examples involving the adverbs alternately and respectively:

(23) John was alternately hot and cold.

(24) Mary and Sue are tall and short, respectively.

In support of his analysis of and, Winter points out that for such sentences, the interpretation procedure has to have access to each conjunct "independently". Access 
to their Boolean meet does not suffice. Winter claims further that structure sensitive adverbials such as these are not licensed by or, and from this concludes that the denotations of the disjuncts of an or coordination are not independently retrievable in the process of interpretation.

One challenge to this claim comes from Eggert (2000), who demonstrates that respectively is acceptable with or coordinations in certain environments. Here are two of his examples (all of which are culled from web searches):

(25) In most carbon compounds, an adjacent atom will contribute one to three electrons, which are matched by an equal number from carbon to form a single, double or triple bond, respectively.

Choose the snowflake or sun for winter or summer information, respectively.

Moreover, there is a robust intuition that a variety of cases which are problematic for the Boolean treatment of or are problematic precisely because the interpretation indeed does seem to look "inside" the disjunction, at the disjuncts themselves. Consider for example the case of conditionals with disjunctive antecedents, as illustrated in (27).

(27) If Jane is singing or dancing, then so is Jennifer.

$=$ If Jane is singing, then Jennifer is singing, and if Jane is dancing, then Jennifer is dancing. ${ }^{6}$

More pertinently, the case of free choice disjunction, to which we will turn immediately below, also seems to demonstrate exactly this property of "structure sensitivity," with the interpretation requiring that the modal in some sense have access to each disjunct independently.

I conclude, then, that there are no grounds to dismiss the set-formation analysis of or coordinations. Rather, the emergence of an analysis of or parallel to Winter's set-formation analysis of and provides grounds to pursue the possibility of a unified analysis of coordination as set formation.

\section{Modals and or Without Negation}

\subsection{The Problem of Free Choice Permission Sentences}

Consider sentence (28):

Jane may sing or dance.

This sentence, like the others considered so far, has two interpretations. These are represented below:

$$
\diamond(\text { jane sing }) \wedge \diamond(\text { jane dance }) \quad \text { "free choice reading" }
$$




$$
\diamond(\text { jane sing }) \vee \diamond(\text { jane dance) } \quad \text { "disjunctive reading" }
$$

Sentences like (28) pose a central problem for any Boolean analysis of $o r$. For while the disjunctive reading is straightforwardly derivable, the (generally more salient) free choice reading is not derivable on any account based on set union. This includes the account proposed here: under the Set Formation analysis, only the disjunctive truth conditions of (28) are derivable.

In the recent literature, a variety of proposals have been offered, aimed at solving the free choice problem. All of these proposals involve a departure from the Boolean analysis of or. Zimmermann (2000) proposes a modal analysis of disjunction. On his account, an or coordination 'A or B' has the semantics ' $\triangle \mathrm{A} \& \diamond \mathrm{B}$ '. Aloni (2002) offers instead a semantics based on alternatives; her solution to the free choice problem involves a new semantics for modals which is sensitive to the alternative sets generated by their argument. In Simons (2005), I argued for $o r$ as a set formation operator, and then proposed further that the semantics of or also requires that this set serve to "divide up" a given domain.

All of these accounts take the free choice permission sentence as the central case to be explained, and all succeed in deriving its truth conditions. ${ }^{7}$ But the accounts also share the same problem: negation. ${ }^{8}$ The problem comes down to this. Any account which directly assigns to (28) above the truth conditions in (29) will, unless some ad hoc modification is made, assign to the negation of (28) the negation of (29), i.e. (31):

$$
\begin{aligned}
& \neg[\diamond \text { (jane sing }) \wedge \diamond(\text { jane dance })]= \\
& \neg \diamond \text { (jane sing }) \vee \neg \diamond(\text { jane dance })
\end{aligned}
$$

i.e. Either Jane is not permitted to sing or Jane is not permitted to dance.

But, as we have already observed, this is only one of the readings of the negation of (28), and not the most salient reading either. So here is the dilemma: Accounts which allow for the derivation of the free choice reading of sentences like (28) don't get the right readings for the negated cases; but a Boolean analysis, which does get the right readings for the negated cases, cannot derive the free choice readings.

This is the dilemma which I now propose to resolve.

\subsection{Disjunction and Symmetry}

In my earlier paper on this topic (Simons 2005) I proposed, as noted above, that the truth conditions of a sentence containing an or coordination impose a special requirement on the set which the coordination introduces. ${ }^{9}$ The set must serve to nonvacuously divide up some domain, with the relevant domain determined by the semantic environment in which the coordination occurs. This analysis was a way of expressing a more basic idea: that in the interpretation of a disjunction, each dis junct is required to make its own independent contribution to the truth conditions of the sentence in which it occurs. ${ }^{10}$ No disjunct can be vacuous; each must impact 
somehow on the interpretation. We see effects of this sort even looking at unembedded clausal disjunctions, which are subject to certain acceptability requirements. For example, a disjunction like (32), in which one disjunct entails another, is generally unacceptable.

(32) Either she wore a dress or she wore a red dress.

This is understandable in terms of a requirement that each disjunct have some independent effect on the truth conditions.

There is a further element to this idea about the basic workings of or. Not only must each disjunct make some contribution to the truth conditions; but each must make the same kind of contribution. In other words, there is some kind of symmetry requirement involved in the interpretation of an or coordination.

Rather than trying to incorporate this requirement into the truth conditions, as I did before, I will here formulate a separate condition which expresses this basic idea. I call it the Symmetry Condition, for obvious reasons:

\section{The Symmetry Condition}

Let $\mathrm{A}$ be the maximal alternatives set generated by a disjunction $d_{1}$ or ... or $d_{\mathrm{n}}$. Under normal conversational circumstances, the disjunction is conversationally licensed only if there is some salient property $\mathrm{P}$ such that for all $a \in A, P(a)$.

(The maximal alternatives set generated by a disjunction is the set to which union is applied in the course of the derivation i.e. the set resulting from the final application, if any, of Independent Composition.)

In what follows, I will demonstrate that the truth conditions of modal/neg/or sentences derivable via the Set Formation analysis straightforwardly provide a property by virtue of which the Symmetry condition can be met. But the truth conditions straightforwardly derivable for modal/or sentences without negation don't provide such a property. The free choice interpretations of these sentences, I will argue, are non-compositional strengthenings assigned to these sentences to guarantee satisf action of Symmetry.

\section{Working out the Details}

\subsection{How modal/neg/or Interactions Satisfy Symmetry}

Consider again sentence (1):

(1) Jane may not sing or dance. 
On its neither reading, the sentence has the truth conditions shown in (34). These truth conditions can equivalently be expressed as in (35).

$$
\neg \exists \mathrm{w} \in \mathrm{ACC}_{\mathrm{w}}: \mathrm{w} \in[\mathrm{js}] \cup[\mathrm{jd}]
$$

$$
\mathrm{ACC}_{\mathrm{w}} \cap \cap[\mathrm{js}]=\varnothing \text { and } \mathrm{ACC}_{\mathrm{w}} \cap[\mathrm{jd}]=\varnothing
$$

This reformulation shows that these truth conditions impose a parallel condition on each disjunct: each must have an empty intersection with $\mathrm{ACC}_{\mathrm{w}^{*}}$, the set of deontically accessible worlds. This condition makes salient a property which is symmetrically satisfied by the disjuncts, namely, the property of non-overlap with $\mathrm{ACC}_{\mathrm{w}}$. Thus, the truth conditions themselves provide a property which allows for the satisfaction of Symmetry.

As you will recall, sentence (2), on its most salient reading, shares the truth conditions of the neither reading of (1).

Jane must not sing or dance.

So for one reading of this sentence too, Symmetry is straightforwardly satisfied.

You will also recall, though, that sentence (2) gave rise to a problem (see discussion atend of section 1.2.). The Set Formation analysis seemed to allow for the derivation of the unattested truth conditions in (36).

$$
\left.\mathrm{ACC}_{\mathrm{w}^{*}} \subseteq[\neg \mathrm{j} s] \cup \mathbb{[} \neg \mathrm{jd}\right]
$$

We have not yet explained how the derivation resulting in these truth conditions is ruled out.

One possibility is that the derivation is ruled out by virtue of considerations of Symmetry. Note that the truth conditions in (36) do not provide a property which necessarily holds symmetrically of the disjuncts. They could be satisfied, for example, in the following situation:

$$
\mathrm{ACC}_{\mathrm{w}^{*}} \subseteq[\neg \mathrm{j} s] \& \mathrm{ACC}_{\mathrm{w}^{*}} \cap[\neg \mathrm{jd}]=\varnothing
$$

So, it is possible that the derivation which results in the truth conditions in (36) is ruled out given the availability of an alternative derivation which results in truth conditions which allow for the satisfaction of Symmetry.

\subsection{Strengthening affirmative cases to satisfy Symmetry}

We turn now to the problematic free choice case, as represented by sentence (28).

Jane may sing or dance. 
Under the Set Formation analysis, only one set of truth conditions is derivable for this sentence. These are the disjunctive truth conditions, represented in (38).

$$
\left.\mathrm{ACC}_{\mathrm{w}^{*}} \cap(\text { [jane sing }] \cup[\text { jane dance }]\right) \neq \varnothing
$$

However, these truth conditions are derivable in two different ways; and the composition strategy used makes a difference, because each gives rise to a distinct maximal alternatives set. Here, I want to focus on just one of the possibilities, the one in which we apply union at the VP level, before composing the modal with its argument. (We return to the other case below.) In the case under consideration, the maximal alternatives set will be:

$$
\text { \{[jane sing],[jane dance]\} }
$$

Now, observe that the ruth conditions in (38) fail to provide a property to satisfy Symmetry with respect to the alternatives in (39). Moreover, as we'll see below, the alternative composition strategy also does not straightforwardly satisfy Symmetry. So what is the way out?

I propose that when all else fails, the interpretation procedure moves to strengthen the compositionally derivable truth conditions in order to force satisfaction of Symmetry. We start with a property which is made salient by the truth conditions: the property of non-empty intersection with $\mathrm{ACC}_{\mathrm{w}}$. We then assign to (28) strengthened truth conditions in which this property is symmetrically assigned to both alternatives, i.e.:

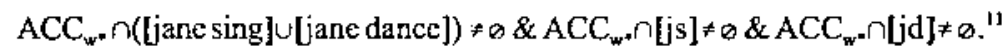

These are exactly the truth conditions of the free choice interpretation. Note, by the way, that this account of how the free choice interpretation arises accounts for the fact that the non-Boolean interpretation entails the Boolean interpretation: it is a strengthening of it.

Let's now turn to the interaction of must and or, as exemplified in sentence

Jane must sing or dance.

This sentence also has two possible readings. We focus first on the free choice reading ${ }^{12}$, under which the sentence has the truth conditions represented in (42):

$\mathrm{ACC}_{\mathrm{w}^{*}} \subseteq([\mathrm{j} s] \cup[\mathrm{jd}]) \& \mathrm{ACC}_{\mathrm{w}^{*}} \cap[\mathrm{j} s] \neq \varnothing \& \mathrm{ACC}_{\mathrm{w}^{*}} \cap[\mathrm{jd}] \neq 0$

Paraphrase: Jane has an obligation which is satisfied either by singing or by dancing.

As with the may/or sentence, the truth conditions derivable for the sentence under the Set Formation analysis are weaker than those attested. In fact, the derivable truth 
condition consists of just the first conjunct of (42). The derivation, assuming the LF in (43), is shown in (44).

$$
\text { LF: [must [jane [sing or dance]]] }
$$

(i) sing or dance $=\Longrightarrow\{$ [sing],[dance] $\}$

(ii) jane sing or dance $==>_{\text {Ind comp }}\{$ [jane sing], [jane dance] $\}$

(iii) APPLY UNION $==>\quad \cup\{$ [jane sing], [jane dance] $\}$

(iv) must jane sing or dance $=>$ [must] $(\cup\{$ [jane sing], [jane dance] $\})$

So now we must explain how the observed truth conditions are arrived at.

As a first step, note that the derivable truth conditions do not provide any property to satisfy Symmetry. The actual truth conditions, though, clearly do impose a condition symmetrically on the two members of the maximal alternatives set. So, as before, I presume that the observed truth conditions are derived from the initially derivable truth conditions via strengthening.

However, a question arises. The truth conditions initially derivable for (41) - the first conjunct of (42) - would seem to make salient the property of being a superset of $\mathrm{ACC}_{\mathrm{w}^{*}}$, not that of having a non-empty intersection with $\mathrm{ACC}_{\mathrm{w}^{*}}$ Wouldn't we then expect the truth conditions to be strengthened to (45), rather than to $(42)$ ?

$$
\mathrm{ACC}_{w^{*}} \leftarrow[j \mathrm{j}] \& \mathrm{ACC}_{w^{*}} \subseteq[\mathrm{jd}]
$$

In answer, I think I must say that the derivable truth conditions simply make salient some set of possible relations between sets of worlds. The interpretation procedure then seeks the weakest strengthening, utilizing some such relation, which will satisfy Symmetry. It is also plausible that the procedure avoids strengthenings which would make the utterance truth conditionally identical to a competing form. Note that the truth conditions in (45) are straightforwardly derivable for sentence (46), with and.

$$
\text { Jane must sing and dance. }
$$

Hence, assignment of these truth conditions to (41) would be dispreferred.

Having introduced the option of strengthening, we need to return one last time to the must/neg/or composition puzzle. The puzzle concerned sentence (2), repeated here from above.

\section{(2) Jane must not sing or dance.}

We observed that there is a composition strategy apparently available for this sentence (see (17) above) which would give rise to the unattested truth conditions in (47). 
$\mathrm{ACC}_{\mathrm{w}} *[\neg \mathrm{j} \mathrm{s}] \cup[\neg \mathrm{jd}]$

"Jane must either not sing or not dance."

Earlier, I argued that this strategy, and hence this interpretation, is ruled out because the truth conditions in (47) provide no property which would serve to satisfy Symmetry. However, now that we've introduced the option of strengthening, it seems we should be able to use that strategy here too. So, we could strengthen (47) to (48):

$\mathrm{ACC}_{\mathrm{w}} *\left[[-\mathrm{js}] \cup[\neg \mathrm{jd}] \& \mathrm{ACC}_{\mathrm{w}} \cdot \cap[\neg \mathrm{js}] \neq \varnothing \& \mathrm{ACC}_{\mathrm{w}} \cdot \cap[\neg \mathrm{jd}] \neq \varnothing\right.$

"Jane is obliged to not sing or not dance; not singing and not dancing are both permissible."

But this is not a reading of (2) either. So we are left with this question: Why can't we use strengthening to remedy the failure of Symmetry in this case?

Various possible answers suggest themselves. One is that the adoption of an alternative composition strategy is preferable to use of the strengthening, which should be seen as a last resort. However, at this point I must concede that it is possible that the derivation which results in (47) may be ruled out for independent reasons.

\subsection{Disjunctive readings, Symmetry, and the Genuineness constraint}

So far, in discussing whether or not readings satisfy Symmetry, we have considered only non-disjunctive readings. As soon as we turn to dis junctive readings, we seem to encounter a problem, for surely all such readings fail to provide a property which will satisfy Symmetry. Consider a simple clausal disjunction:

$$
\text { Jane sang or Harriet danced. }
$$

This is true at a world $\mathrm{w}^{*}$ just in case:

$$
w^{*} \in u\{[j s],[h d]\}
$$

i.e. just in case $\mathrm{w}^{*}$ is a member of one disjunct or the other. The truth conditions provide no property which is required to hold symmetrically of the two dis juncts.

But there is a non-truth-conditional property which can serve this role. As Zimmermann (2000) notes, each disjunct of an unembedded dis junction is generally taken to be an epistemic possibility for the speaker. In fact, if this assumption conflicts with other information which the interpreter has, utterance of the dis junction may well be taken to be defective in some way. ${ }^{13}$ Zimmermann calls this the Genuineness constraint.

We can reformulate the Genuineness constraint in terms of alternatives sets generated by a disjunction, as follows: 
Genuineness constraint

Let $\mathrm{A}$ be an unembedded maximal alternatives set generated by a disjunction $d_{1}$ or...or $d_{\mathrm{n}}$. Under normal conversational circumstances, all $\mathrm{a} \in \mathrm{A}$ are taken to be epistemic possibilities for the speaker.

The property of being an epistemic possibility for the speaker is thus attributed symmetrically to each disjunct. Thus, we can see Genuineness as arising in the service of Symmetry: if no satisfying property is made salient by the truth conditions, assume Genuineness in order to satisfy Symmetry. ${ }^{14}$

It is presumably not accidental that Genuineness arises as a requirement only when the maximal alternatives set is not embedded under any operator. When it is so embedded, Symmetry has to satisfied in some sense relative to that operator. In particular, when the maximal alternatives set is embedded directly under a modal operator, then the property satisfying Symmetry must be a relation between the disjuncts and the relevant set of accessible worlds. The current account remains unsatisfactory in that it does not quite capture this dependency between or coordinations and the operators which embed them. I hope to remedy this in future work.

\section{Concluding remarks}

The proposal made here for the analysis of or coordinations has two parts. The basic semantic proposal is contained in the Set Formation analysis laid out in section 1.1. According to this analysis, or triggers the construction of a set whose members are the denotations of its disjuncts. This set may compose with an argument via Independent Composition; or may be simplified by set union, with composition then proceeding in the normal way. I have demonstrated that different composition strategies allow for the derivation of different readings. In particular, we can account in this way for the well known fact that disjunctions can scope either over or under an apparently wider scope operator, as illustrated by the ambiguities we have considered here. More work needs to be done to ensure that this system does not overgenerate.

But the Set Formation analysis cannot, by itself, account for some of the most problematic readings of or sentences, in particular, for the free choice readings of sentences like (28) and (41) above. These anomalous readings, I have argued, show us the effects of the Symmetry Condition on the use of or coordinations. I have claimed that this condition is always in effect, but that in the majority of cases, it is straightforwardly satisfied. Free choice readings, which in all cases entail the interpretations derivable by the Set Formation analysis, are claimed to arise as a result of a process of strengthening motivated by the need to satisfy Symmetry. 


\subsection{Why not a more standard pragmatic approach?}

My analysis of free choice readings concedes that these are not derived by straightf orward compositional processes. Once this concession is made, one might wonder: why not derive them as familiar sorts of conversational implicatures? Kratzer and Shimoyama (2002) adopt this strategy to account for the free choice effects associated with indefinites in certain environments. So it might seem natural to extend this to the case of $o r$.

One fundamental reason why I do not adopt this strategy is this: In the interpretations assigned to free choice sentences, the "f ree choice component" is in no way separable from "what is said." It is not the case, as with other conversational implicatures of all kinds, that one can separate what was said, strictly speaking, from what was implied or conveyed. As illustration, consider the following scenario. Suppose I write on my course syllabus:

(52) To pass this course, you may write a term paper of 20 pages, or three papers of 6 pages each.

Now imagine the following conversation between two of my students:

The Conversationalist:

The Stickler:
That's interesting, the syllabus says there are two options for papers for this course.

Well no, what the syllabus says is that one of those two things is permitted. But I suppose it implies that we can do either.

What The Stickler says does not seem to be justifiable (or even unjustifiable) nitpicking; it seems to be false. The syllabus indeed says that there are two options; there is no distinct "strict sense" in which the sentence can be taken. If the sentence is mistakenly taken disjunctively, then there is no free choice reading at all; if it is correctly taken as a free choice statement, then there is no "underlying" dis junctive reading.

The lack of a distinction in free choice sentences between a "strict" sense and the full communicative value leads me to the conclusion that an analysis along the Kratzer and Shimoyama line, which generates non-free-choice truth conditions and then adds on the free choice component as a conversational inference, is inappropriate here. ${ }^{15}$

\subsection{What kind of constraint is Symmetry?}

This brings us to a crucial question: If Symmetry is not conceived as a kind of Gricean pragmatic principle, then what kind of principle is it?

First, the principle, as I currently conceive of it, is conventional, not conversational. That is, I understand it as a constraint which is specifically associated 
with the word or (or perhaps somewhat more generally, with expressions which introduce alternatives). I have not attempted to derive the principle from any more general properties of conversation, although perhaps such a derivation is possible. I suspect that the constraint is violable, although only in special circumstances.

Theclosest relative to the Symmetry Condition which I've encountered in the literature is the Homegeneity Constraint, posited by some authors for the interpretation of distributive predicates (see Loebner 1987, Schwarzschild 1994, Beck 2001). This constraint is offered as a definedness constraint on distributive predication, and is formulated by Beck as follows:

$$
\begin{aligned}
* P(A)= & 1 \text { iff } \forall x[x \in A \rightarrow P(x)] \\
& 0 \text { iff } \forall x[x \in A \rightarrow \neg P(x)] \\
& \text { undefined otherwise. }
\end{aligned}
$$

This constraint does not fall out of the semantics of distributivity, but is imposed as a condition on admissible truth conditions. There is certainly some informal similarity between this condition and my Symmetry condition: both conditions have the effect of strengthening truth conditions on the basis of a requirement that every member of a relevant set share a given property.

My utilization of a special principle to strengthen truth conditions is also reminiscent of Chierchia's (2004) treatment of Scalar Implicature. In his proposal, these implicatures are calculated locally, in the course of semantic composition, with strengthened interpretations being fed back in to the semantic composition process. It is clear that once the principle generating scalar implicatures is taken to work in this way, it is no longer being understood as a conversational principle in the Gricean sense. ${ }^{16}$ Thus, acceptance of this analysis means accepting that there are processes working in tandem with semantic composition which are neither a part of ordinary compositional semantics, nor a part of post-semantic pragmatic inferencing. We might think of these processes as being functional. They are understandable in terms of familiar ideas such as maximizing informativity; but they are not driven by expectations of cooperation, as ordinary pragmatic processes are.

\section{Endnotes}

${ }^{1}$ Throughout the paper, I will adopt a simple accessibility semantics for modals. Nothing hinges on this. The proposal is compatible with more complex analyses. Throughout, ' $\mathrm{ACC}_{\mathrm{w}}$ ' denotes the set of worlds deontically accessible from $\mathrm{w}$ '.

${ }^{2}$ This proposal constitutes a deviation from a strict conception of compositionality, as it assumes that it is possible to look into the derivational history of the denotation of a node. More deviations from strict compositionality will follow.

${ }^{3}$ I am assuming without comment that while negation takes scope over may, must takes scope over negation. This switch in relative scope occurs independently of the interaction with or. Consider sentences (i) and (ii):

(i) Jane may not sing. 
(ii) Jane must not sing.

These both mean the same thing, i.e. that Jane is not permitted to sing. We can represent this only by assuming that the modal and negation switch scopes, as shown in (iii) and (iv).

(iii) $\neg \diamond$ Jane sing

(iv) $\square \neg$ Jane sing

This scope switch is certainly puzzling, and interesting in its own right; but I assume it is tangential to the issue of how disjunction interacts with modals.

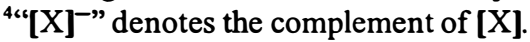

${ }^{5}$ They are the truth conditions for the sentence "Jane must either not sing or not dance," where the negation is clearly phrasal.

${ }^{6} \mathrm{This}$ is only one of the available interpretations.

${ }^{7}$ The different accounts have varying success, however, in deriving correct truth conditions for related sentences, including the variant with must.

${ }^{8}$ This point is nicely demonstrated by Alonso-Ovalle (2004).

${ }^{9}$ That is, on the maximal alternatives set introduced by the coordination. See below.

${ }^{10}$ The very same fundamental idea is also expressed in a much earlier proposal of mine concerming disjunction, made in my $1998 \mathrm{Ph} . \mathrm{D}$. dissertation, published as Simons (2000).

${ }^{11}$ I include the initial conjunct, representing the compositionally derivable truth conditions, for perspicuity; but of course this conjunct is redundant, as it is entailed by each of the additional conjuncts.

${ }^{12}$ This reading of the must sentence isn't traditionally called a free choice reading, but I think the name is appropriate: the sentence says that Jane is free to choose either action to fulfil her obligation.

${ }^{13}$ But not necessarily. One has to look at the total communicative situation in which the utterance is made.

${ }^{14}$ One might speculate that in cases where Genuineness can felicitously be suspended, some other salient property is available for the satisfaction of Symmetry.

${ }^{15}$ Additionally, the particular pragmatic argument provided by Kratzer and Shimoyama (2002) for generating the free choice inference is, in my view, problematic. However, to argue this point, I would have to rehearse the details of their proposal, which would take me beyond the space constraints of this paper.

${ }^{16} \mathrm{This}$ is my own view; I don't know if Chierchia would agree with this.

\section{References}

Aloni, Maria: 2002, 'Free Choice in Modal Contexts', in Arbeitspapiere des Fachbereichs Sprachwissenschaf, University of Konstanz. [Available at http://www.xs4all.nl/ wander/aloni/]

Alonso-Ovalle, Luis: 2004. 'Equal Rights for Every Disjunct! Quantification over Alternatives or Pointwise Context Change?' NELS 35.

Beck, Sigrid: 2001. 'Reciprocals are Definites', Natural Language Semantics 9, 69138. 
Chierchia, Gennaro: 2004, 'Scalar Implicatures, Polarity Phenomena and the Syntax/Pragmatics Interface', in A. Belletti (ed.) Structures and Beyond, OUP.

Eggert, Randall: 2000, 'Grammaticality and Context with respect to and... and or...respectively', CLS 36.

Kratzer, Angelika and Junko Shimoyama: 2002, 'Indeterminate Pronouns: the View from Japanese', in Proceedings of the Third Tokyo Conference on Psycholinguistics, 1-25. [Longer version available at Semantics Archive http://semanticsarchive.net/]

Partee, Barbara and Rooth, Mats: 1983, 'Generalized Conjunction and Type Ambiguity', in R. Bäuerle, C. Schwarze, and A. von Stechow (eds.) Meaning, Use and Interpretation of Language, de Gruyter, Berlin.

Schwarzschild, Roger: 1994, 'Plurals, Presuppositions, and the Sources of Distributivity', Natural Language Semantics 2, 201-248.

Simons, Mandy: 2000. Issues in the Semantics and Pragmatics of Disjunction, Garland Publishing Inc, New York.

Simons, Mandy: 2005, 'Dividing Things Up: the Semantics of or and the Modal/or Interaction', Natural Language Semantics 13:271-316.

Winter, Yoad: 1995, 'Syncategorematic Conjunction and Structured Meanings', Proceedings of Semantics and Linguistic Theory (SALT) 5.

Winter, Yoad: 2000, 'On Some Scopal Assymetries of Coordination', in H. Bennis et al. (eds.) Proceedings of the KNAW conference on Interface Strategies.

Zimmermann, Thomas Ede: 2000, 'Free Choice Disjunction and Epistemic Possibility', Natural Language Semantics 8, pp. 255-290. 